\title{
The Structure Optimization of Diesel Injection Pump Based on DOE
}

\author{
Wu Xinying \\ Navy university of engineering \\ Wuhan,430033, china
}

\author{
Ouyang Guangyao \\ Navy university of engineering \\ Wuhan, 430033, china
}

\begin{abstract}
The fuel supply quantity of high-pressure pump and the fuel supply quality from constant pressure valve to high pressure vitta was very important to capacity of the diesel engine. In this paper, the model of the fuel injection system is established by Hydism and the model is integrated with Isight in DOE research. According to the DOE results, two optimization interdigitations were used to optimize the fuel injection system to improve the cubage efficiency of highpressure pump and the flow capacity of delivery valve. The optimization results showed that the united use with system model and DOE in optimization design of the fuel injection system is effectively and the cubage efficiency of pump could be promoted $5.97 \%$ and the flow capacity of delivery valve could be promoted $24.65 \%$.
\end{abstract}

Keywords-Fuel injection system, System model, DOE, Cubage efficiency, Flow capacity, Optimization design

\section{INTRODUCTION}

In the fuel injection system, the fuel supply quantity lies on the cubage efficiency of high-pressure pump and the fuel supply quality from constant pressure valve to high pressure vitta lies on the flow area of ball valve. It is very important that how to choose appropriate structural parameters and characteristic parameters of system to get the best cubage efficiency of high-pressure pump and flow capacity of delivery valve[[1-2].

It is very complex and inefficiency with manual programming to study influencing factors of the system. So the paper build the fuel-injection model with Hydism and carries out sensitivity analysis of structural parameters and characteristic parameters to the cubage efficiency and flow capacity with DOE(design of experiment) of Isight software. The ANOVA (Analysis of Variance), main effect and interaction effect were analyzed from DOE results. After that two optimization interdigitations were used to optimize the main factors of system[3]

\section{MOdel Of Fuel INJECTION SyStem}

Because autobody panels emphasis curved surface whole artistic effects, measurement accuracy is not the first problem considered in the course of the measuring car body, but trying to make the development time shorter [4].

According to the characteristics of the diesel engine, the model of the fuel injection system is established by dividing it into components including high pressure pump, constant pressure valve, high pressure vitta and injector, all of which are represented by elements such as volume, hydraulic valve, piston, orifice, pipeline, and cam. The system is illustrated in Fig.1.

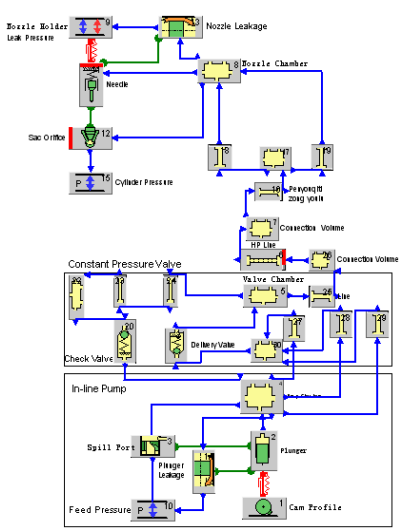

Figure 1. Fuel injection system model

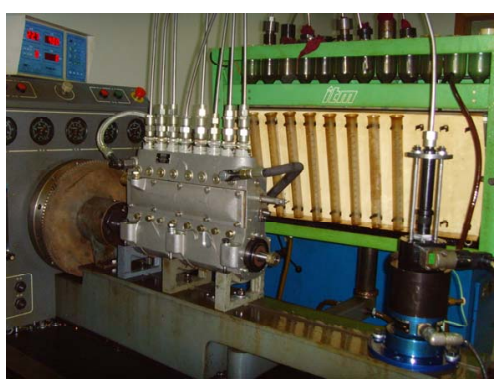

Figure 2. High-pressure pump test-bed

To verify the veracity of models, the fuel pressures at the outlet of delivery valve of high-pressure pump has been measured in high-pressure pump test-bed (Fig.2) with cam speed being $1000 \mathrm{r} / \mathrm{min}$ and the fuel supply quantity in one cycle being $450 \mathrm{~mm} 3$.

As illustrated in Fig.3, the difference between the maximal fuel pressure of simulation results and that of test results is $1.8 \%$. The simulation model is validated.

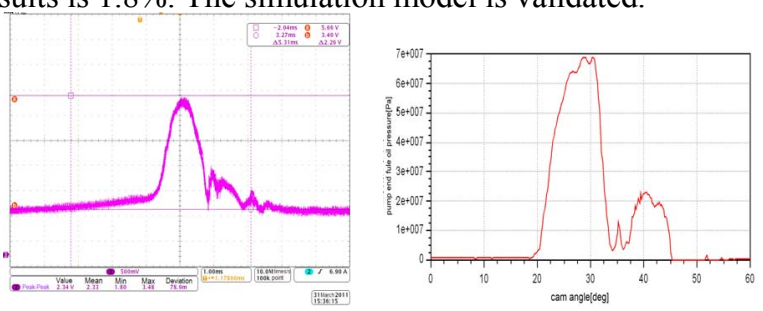

Figure 3. Comparison of fuel pressure of test results and simulation results 


\section{DOE RESEARCH}

\section{A. DOE process integration}

The fuel injection model is integrated with Isight in DOE research. The data is exchanged between Hydism and Isight. Firstly, the simulation results of Hydism model is transmitted to Isight and the results is stored in Isight. Then the design parameters of Hydism model are changed by Isight according to test schemes and the new simulation results could be gotten. The integrated process is illustrated in Fig.4[5].

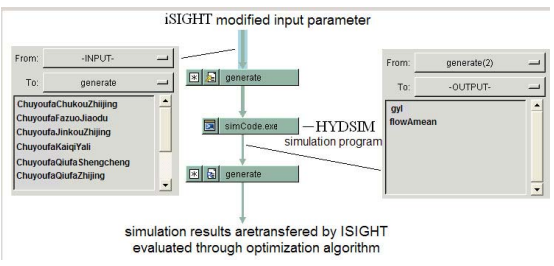

Figure 4. Data flow of HYDSIM and Isight

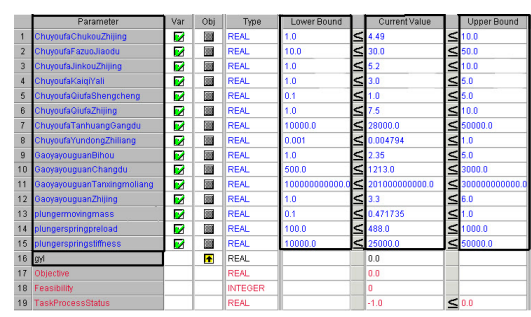

Figure 5. Configure parameters

\section{B. Design parameters}

According to the structural characteristics of high pressure pump, the design parameters are determined which are illustrated in Fig. 5. The maximal fuel quantity at outlet of delivery valve and the mean value of flow area at channel restriction of ball valve are determined respectively as objectives of cubage efficiency and flow capacity.

\section{Test schemes}

Six kinds of scheme are determined basing on the test method, the test times and the level values. The paper chooses Orthogonal Arrays and Latin Hypercube.

TABLE I. THE TEST SCHEMES OF DOE

\begin{tabular}{|c|c|c|c|c|c|c|}
\hline scheme & $\mathbf{1}$ & $\mathbf{2}$ & $\mathbf{3}$ & $\mathbf{4}$ & $\mathbf{5}$ & $\mathbf{6}$ \\
\hline $\begin{array}{c}\text { Test } \\
\text { method }\end{array}$ & $\mathrm{OA}$ & $\mathrm{OA}$ & $\mathrm{OA}$ & $\mathrm{OA}$ & LH & LH \\
\hline $\begin{array}{c}\text { Number of } \\
\text { level }\end{array}$ & 3 & 3 & 3 & 3 & - & - \\
\hline $\begin{array}{c}\text { Range of } \\
\text { level }\end{array}$ & $\pm 5 \%$ & $\pm 7 \%$ & $\pm 8 \%$ & $\pm 9 \%$ & $\pm 8 \%$ & $\pm 9 \%$ \\
\hline Test times & 243 & 243 & 243 & 243 & 520 & 910 \\
\hline
\end{tabular}

(4)DOE results

Due to limitations on space, the paper only gives the cubage efficiency results of scheme 1.

The Pareto result (Fig.6) showed that the cubage efficiency was most sensitive to the hydraulic diameter and the length of high pressure vitta, the maximum lift and the opening pressure of delivery valve ball, the preload of plunger spring.

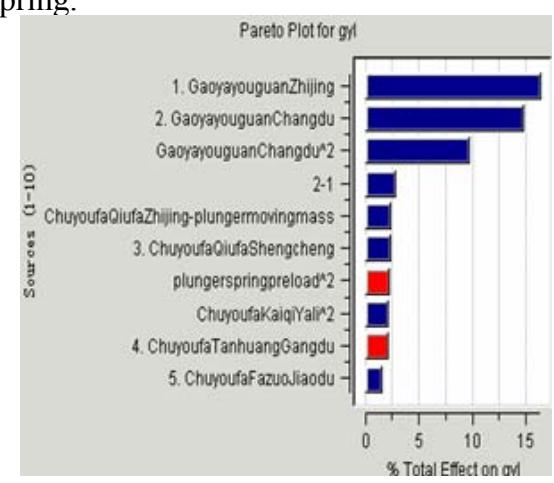

Figure 6. Pareto of scheme 1

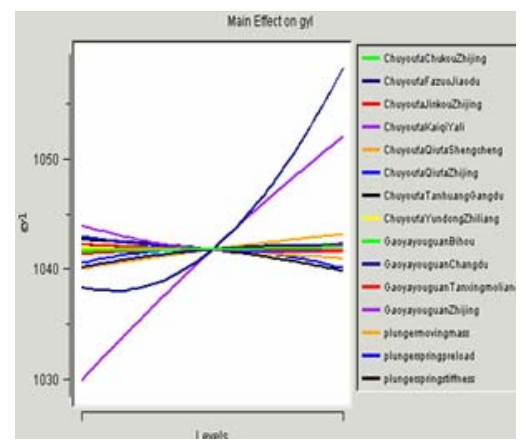

Figure 7. Main effect of scheme 1

The main effect result (Fig.7) showed that the slope of titration curve which is bigger means the parameter has more important effect on the cubage efficiency.

As illustrated in Tab.2 and Tab.3, the paper gives the important design parameters of cubage efficiency and flow capacity of all schemes.

The cubage efficiency was most sensitive to the hydraulic diameter and the length of high pressure vitta, the maximun lift and the opening pressure of delivery valve ball, the plunger equivalent moving mass.

The flow capacity of delivery valve was most sensitive to the plunger equivalent moving mass, the half-angle of delivery valve seat, the delivery valve equivalent moving mass, the diameter of delivery valve ball and the hydraulic diameter of high pressure vitta

TABLE II. IMPORTANT DESIGN PARAMETERS OF CUBAGE EFFICIENCY

\begin{tabular}{|c|c|c|c|c|c|}
\hline Scheme 1 & L D & L L & L B & P S P & O P B \\
\hline Scheme 2 & L D & L L & L B & O P B & P M \\
\hline Scheme 3 & L D & L L & L B & O P B & P M \\
\hline Scheme 4 & L D & L L & L B & O P B & P M \\
\hline Scheme 5 & L L & L D & V S A & B D & P M \\
\hline Scheme 6 & L D & L L & L B & B D & P M \\
\hline
\end{tabular}


TABLE III. IMPORTANT DESIGN PARAMETERS OF FLOW CAPACITY

\begin{tabular}{|l|c|c|c|c|c|}
\hline Scheme 1 & P M & V S A & B D & B M & L D \\
\hline Scheme 2 & P M & V S A & B M & B D & L D \\
\hline Scheme 3 & P M & V S A & B M & B D & L D \\
\hline Scheme 4 & P M & V S A & B M & L D & L D \\
\hline Scheme 5 & P M & V S A & B M & B D & B D \\
\hline Scheme 6 & P M & V S A & B M & B D & L D \\
\hline
\end{tabular}

\section{OPTIMIZATION DESIGN}

In order to improve the cubage efficiency of highpressure pump and the flow capacity of delivery valve, the Isight was used to optimize the structural parameters and characteristic parameters of pump and high pressure vitta.

(1)Optimization schemes

Two optimization interdigitations were used to optimize the system with consideration on the optimal strategy of Isight.

Scheme 1: Directed Heuristic Search with NLPQL

Scheme 2: MMFD

(2) Optimization results

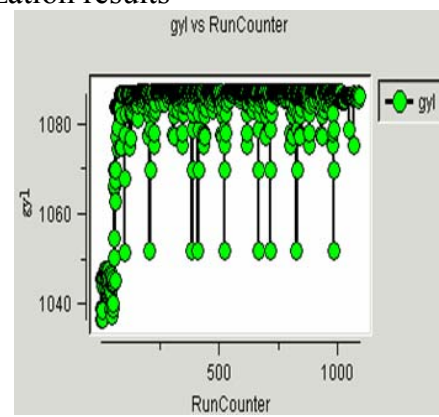

Figure 8. Optimization process of scheme of cubage efficiency of pump

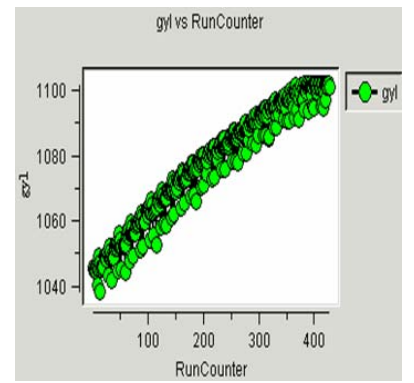

Figure 9. Optimization process of scheme of cubage efficiency of pump

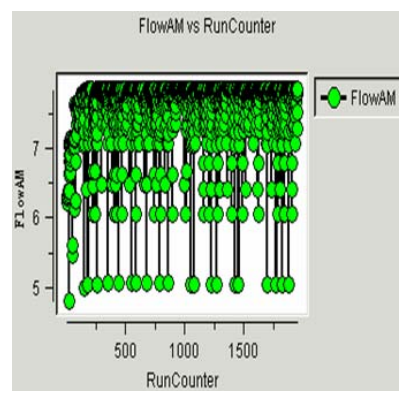

Figure 10. Optimization process of scheme of flow capacity of delivery valve

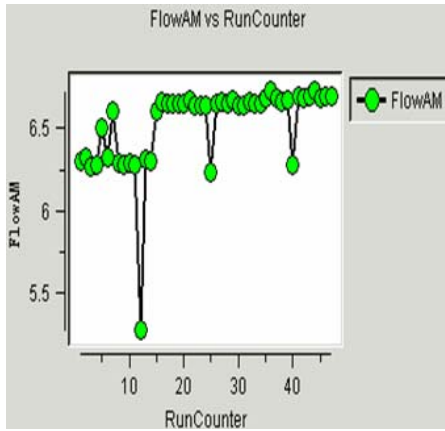

Figure 11. Optimization process of scheme of flow capacity of delivery valve

As illustrated in Fig.8 and Fig.9, the cubage efficiency of pump could be respectively promoted $4.4 \%$ and $5.97 \%$ in scheme 1 and scheme 2 . The flow capacity of delivery valve could be respectively promoted $24.65 \%$ and $6.82 \%$ in scheme 1 and scheme 2, as illustrated in Fig. 10 and Fig.11. The cubage efficiency and the flow capacity of delivery valve all tended to rise, but the former at a modest rate and the latter increased by a wide margin .

\section{CONCLUSION}

The cubage efficiency was most sensitive to the hydraulic diameter and the length of high pressure vitta, the maximun lift and the opening pressure of delivery valve ball, the plunger equivalent moving mass.

The flow capacity of delivery valve was most sensitive to the plunger equivalent moving mass, the half-angle of delivery valve seat, the delivery valve equivalent moving mass, the diameter of delivery valve ball and the hydraulic diameter of high pressure vitta.

The cubage efficiency of pump could be promoted $5.97 \%$ and the flow capacity of delivery valve could be promoted $24.65 \%$. The cubage efficiency and the flow capacity of delivery valve all tended to rise, but the former at a modest rate and the latter increased by a wide margin .

The united use with system model and DOE in optimization design of the fuel injection system is effective in promoting the cubage efficiency of high pressure pump and the flow capacity of delivery valve.

\section{REFERENCES}

[1] JIA Xi-yin; LI Xiao-bo.Fuel Oil Injection and Adjust of Diesel.Harbin: Harbin Engineering University Publisher [M], 2002, PP44-69

[2] ZHANG E. Modern Design Theory and Method, Beijing: The Science Publisher [M], 2007, PP: 24-68

[3] YANG Ming-sheng; LUO Chang-tong. The Principle and Methods and Solution Software of the Optimization, Beijing: The Science Publisher [M], 2006, PP: 43-52

[4] DOE Technology of Isight [EB/OL], www.engineous.com : 2008-0418.

[5] The Optimization Function of Isight[EB/OL], www.engineous.com : 2008-04-18. 